\title{
The Structural Characteristics of the Japanese Paperback Book Series Shinsho
}

\author{
Ruri Shimura \\ The University of Tokyo, \\ Graduate School of Education \\ shimshim_rr@hotmail.co.jp \\ Shohei Yamada \\ The University of Tokyo, \\ Graduate School of Education \\ syamada@p.u-tokyo.ac.jp \\ Bin Umino \\ Toyo University, \\ Faculty of Sociology \\ umino@toyo.jp \\ Shin'ichi Toda \\ Toyo University, \\ Faculty of Sociology \\ toda@toyo.jp \\ Kyo Kageura \\ The University of Tokyo, \\ Interfaculty Initiative in Information Studies \\ kyo@p.u-tokyo.ac.jp
}

\begin{abstract}
Background. Books constitute an important and dominant part of the knowledge infrastructure. It is generally held that the form, structural characteristics, and symbolic characteristics of books influence how they are read and how they are understood. Nevertheless, a systematic study of these characteristics of books has yet to be carried out fully.

Method. Focusing on the Japanese paperback book series Shinsho, whose mission is generally defined as making authentic knowledge available to lay readers, we surveyed the structural characteristics of books, i.e. the depth of the segments (chapter, section, subsection, etc.), the density of segments, how segments are numbered and/or titled, and how the structure of books are represented in the table of contents. We describe the overall characteristics, the chronological changes in these characteristics since 1940, and the association between these characteristics and the subject content of the book.
\end{abstract}


Results. It was observed that as time passed, the density of segments increased in general and converged to the current standard, which consists of three levels of segments (chapter, section, and subsection), among which the top two levels are indicated in the table of contents. Books that deal with literature, however, have a significantly lower density of segments.

Contributions. This study has shown that the structure of Shinsho has changed in the past 70 years. This shed light on how our knowledge infrastructure has been arranged and has changed in a relatively short duration within which we tend to overlook changes.

\section{INTRODUCTION}

Being an essential knowledge infrastructure, books have been the target of numerous studies from various points of view. Chartier (1993) pointed out that the physical aspects of books have an effect on the understanding of texts, as readers access the contents through books with specific physical and symbolic forms. Eisenstein (1987) also suggested that the mode of thinking depends on the structure of books and that the pattern of thinking would change according to their form.

Many studies refer to the physical form and design of books but focus only on those with so-called "monumental" status. For example, Martin (1994) referred to the characteristics of books, but his focus was on the historical origins of the forms of books. McKenzie (1986) also addressed the physical aspect of books, but focussed on historically "important" topics, such as James Joyce's attraction to book forms. Nevertheless, the physical characteristics of books in general have not yet been systematically studied. Most people, even book editors, cannot tell how many chapters and sections there are in a book series such as "Very Short Introductions" (published by the Oxford University Press), how the captions of chapters are shown, or how the chapter/section organisation is represented in the table of contents. With the growing ebook-isation of contents, it is important to understand how knowledge has been organised in the form of books so far.

Against this backdrop, we are currently undertaking a project to clarify the structure and arrangement of books and socially consolidated sets of books. As part of the general project, we surveyed the structural characteristics of Shinsho (a Japanese paperback book series), that is, the depth of segments (chapter, section, subsection, etc.), the density of the segments, how the segments are numbered and/or titled, and how the structure is represented in the table of contents. We describe the overall characteristics as well as the chronological changes in these characteristics since around 1940. In addition, the association between these characteristics and the subject content is also discussed in this paper. As the mission of Shinsho is to make authentic knowledge widely available to lay readers, and as several big Japanese publishers have Shinsho series, delineating the structure of Shinsho constitutes an important step towards clarifying the overall structure and arrangement of books as a knowledge infrastructure. The rest of the paper is organised as follows: Section 2 introduces the target and method of our investigation, Section 3 provides the overall characteristics of Shinsho, Section 4 observes the chronological changes, and Section 5 analyses the association between these characteristics and the subject content. 


\section{DATA AND CHARACTERISTICS}

\section{Data}

Because there is great variation in the content, form, and publication type of books, as a first step it is appropriate to focus on a single type of book in analysing the structural characteristics. We focussed on a coordinated book series planned and produced by publishers, which we shall call "production-oriented books" for brevity. Such productionoriented books target specific readers and provide content according to their objectives. Thus, the production-oriented group of books reasonably corresponds to the function of books and is appropriate for analyzing structural characteristics.

We selected Shinsho as a subject of investigation. Shinsho is a paperback book series published in Japan which, like UK's Pelican Books (Penguin Books Ltd.), provides authentic knowledge for lay readers. In the Japanese publication system, Shinsho is an essential pillar in the transfer of knowledge to lay people. As such, Shinsho is a production-oriented book series, and constitutes a good starting point for observing the structural characteristics of books.

Although there are several Japanese publishing companies that publish Shinsho series, we chose the Iwanami Shinsho series for three reasons. First, Iwanami Shinsho was the origin of Shinsho in Japan. It started in 1938, thus giving it a very long history. Secondly, it has been published continuously to this day. Thirdly, it is widely regarded in Japan as a typical Shinsho series.

We compiled a list of Iwanami Shinsho books based on bibliographic information provided by the National Diet Library of Japan, the National Institute of Informatics of Japan, and Iwanami Shoten, the publisher of Iwanami Shinsho. The list contains a total of 3,018 books published until the end of 2014. We sampled books for which the last digit of the sequential number in order of publishing is 3 ( 1 in 10 books) and investigated 302 books.

\section{Structural Characteristics and Symbolic Characteristics}

We identified, counted, measured, and recorded 53 characteristics.

1. Eight bibliographic elements: title and subtitle, publication date, authors, editors, translators, price, edition and impression, ISBN;

2. Ten physical and physico-symbolic aspects of books: height of content page, width of content page, head margin, tail margin, fore edge margin, width of live area, height of live area, weight of books, thickness of books including cover, thickness of books without cover;

3. Twenty-two physical and additional characteristics of books: total number of pages, number of pages of table of contents, levels of table of contents, single work/collection, existence of Japanese-style colophon [okuzuke], existence of frontispiece, existence of foldout pages, colour printing, number of pictures, number of photographs, number of tables, number of graphs, existence of bibliography, position of bibliography, existence of preface, existence of postscript, existence of emphasis, marking of emphasis, number of indexes, number of index pages, names of indexes, vertical lining/horizontal lining of indexes;

4. Nine characteristics related to symbolic arrangements in a page: vertical lining/horizontal lining of content pages, number of columns in a page, number of lines in a page, number of characters per line, existence of page number, position of page number, existence of headers, frequency of headers, position of headers in content page; 
5. Four arrangements of segments: depth of segments, notation of caption, caption numbering with dotted decimal notation, density of segments.

This paper analyses mainly the fifth set of characteristics, i.e. characteristics related to the structurisation of content. We also analyse the levels of the table of contents because there is a connection between the depth of segments and the levels of the table of contents.

\section{Methods of Measurement}

Five characteristics are analysed in this paper:

1. Depth of segments signifies how many levels of segments a book has. Texts of books are arranged hierarchically, and books are divided into segments (chapters, sections, subsections, etc.). We counted levels of segments as follows: a book with chapters and sections is two levels, and a book with chapters, sections, and subsections is three levels.

2. Notation of caption refers to which type of caption is used to express the start of segments. We recorded captions of segments at all levels.

3. Caption numbering with dotted decimal notation indicates whether captions adopt a point style (for example, 1.1.1, 1.1.2, 1.1.3) or another style. We focussed on the use of point style because this style clearly expresses the hierarchical structure of segments. We judged its use from captions at all levels.

4. Density of segments was approximated by counting the number of segments in 20 pages. We observed the page span from page 91 to page 110. If there were blank pages in that span, we added the same number of pages from page 111 onward.

5. Levels of table of contents means how many levels of segments are indicated in the table of contents. We counted the captions in the table of contents in the same way as the depth of segments.

\section{GENERAL CHARACTERISTICS}

\section{Depth of Segments}

Table 1 shows the depth of segments. Among the 302 books that we investigated, $44.0 \%$ have three levels of segments, and $43.4 \%$ have two. Shinsho has four at most. No book is organised into more than five levels.

As shown in Table 2, 64.2\% of the books have a table of contents that represents the top two levels of segments. No table of contents goes down to four levels of segments. In Table 2, 9999 refers to books without tables of contents.

Table 3 is a cross-tabulation of the depth of segments and the levels of table of contents. There are two types of general forms for Shinsho: one is the two-level-segment and

Table 1. Depth of Segments

\begin{tabular}{cccccc}
\hline level of segments & $\mathbf{1}$ & $\mathbf{2}$ & $\mathbf{3}$ & $\mathbf{1}$ & total \\
\hline number of books & $30(9.9 \%)$ & $131(43.4 \%)$ & $133(44.0 \%)$ & $8(2.6 \%)$ & $302(100.0 \%)$
\end{tabular}

Table 2. Level of Table of Contents

\begin{tabular}{cccccc}
\hline level of table of contents & 1 & 2 & 3 & 9999 & total \\
\hline number of books & $70(23.2 \%)$ & $194(64.2 \%)$ & $36(11.9 \%)$ & $2(0.7 \%)$ & $302(100.0 \%)$
\end{tabular}


Table 3. Level of Segments and Level of Table of Contents

\begin{tabular}{|c|c|c|c|c|c|c|c|}
\hline & \multicolumn{4}{|c|}{ level of segments } & \multirow{2}{*}{ total } \\
\hline & & & 1 & 2 & 3 & 4 & \\
\hline \multirow{12}{*}{$\begin{array}{l}\text { level of table of } \\
\text { contents }\end{array}$} & \multirow{3}{*}{1} & number of books & 29 & 27 & 4 & 0 & 70 \\
\hline & & $\%$ within segments & $96.6 \%$ & $20.6 \%$ & $3.0 \%$ & $0.0 \%$ & - \\
\hline & & \% within total & $9.6 \%$ & $8.9 \%$ & $1.3 \%$ & $0.0 \%$ & $23.1 \%$ \\
\hline & \multirow{3}{*}{2} & number of books & 1 & 91 & 97 & 5 & 194 \\
\hline & & $\%$ within segments & $3.3 \%$ & $69.4 \%$ & $72.9 \%$ & $62.5 \%$ & - \\
\hline & & \% within total & $0.3 \%$ & $30.1 \%$ & $32.1 \%$ & $1.6 \%$ & $64.2 \%$ \\
\hline & \multirow{3}{*}{3} & number of books & 0 & 1 & 32 & 3 & 36 \\
\hline & & \% within segments & $0.0 \%$ & $0.7 \%$ & $24.0 \%$ & $37.5 \%$ & - \\
\hline & & \% within total & $0.0 \%$ & $0.3 \%$ & $10.5 \%$ & $0.9 \%$ & $11.9 \%$ \\
\hline & \multirow{3}{*}{9999} & number of books & 0 & 2 & 0 & 0 & 2 \\
\hline & & \% within segments & $0.0 \%$ & $1.5 \%$ & $0.0 \%$ & $0.0 \%$ & - \\
\hline & & \% within total & $0.0 \%$ & $0.6 \%$ & $0.0 \%$ & $0.0 \%$ & $0.6 \%$ \\
\hline \multirow{3}{*}{ total } & & number of books & 30 & 131 & 133 & 8 & 302 \\
\hline & & \% within segments & $100.0 \%$ & $100.0 \%$ & $100.0 \%$ & $100.0 \%$ & - \\
\hline & & \% within total & $9.9 \%$ & $43.3 \%$ & $44.0 \%$ & $2.6 \%$ & $100.0 \%$ \\
\hline
\end{tabular}

Table 4. Captions

\begin{tabular}{c|r}
\hline \multicolumn{2}{c}{ 1st level } \\
\hline I & $93(30.7 \%)$ \\
第1章 & $52(17.2 \%)$ \\
1 & $42(13.9 \%)$ \\
第一章 & $42(13.9 \%)$ \\
only title & $35(11.5 \%)$ \\
- & $19(6.2 \%)$ \\
第一部 & $6(1.9 \%)$ \\
第I章 & $3(0.9 \%)$ \\
1章 & $2(0.6 \%)$ \\
I章 & $1(0.3 \%)$ \\
前編 & $1(0.3 \%)$ \\
第1部 & $1(0.3 \%)$ \\
第I部 & $1(0.3 \%)$ \\
第一 & $1(0.3 \%)$ \\
第一篇 & $1(0.3 \%)$ \\
第一幕 & $1(0.3 \%)$ \\
第一話 & $1(0.3 \%)$ \\
total & $302(100.0 \%)$ \\
\hline
\end{tabular}

\begin{tabular}{c|r}
\hline \multicolumn{2}{c}{ 2nd level } \\
\hline 1 & $118(43.3 \%)$ \\
only title & $103(37.8 \%)$ \\
- & $27(9.9 \%)$ \\
$(1)$ & $5(1.8 \%)$ \\
第一章 & $5(1.8 \%)$ \\
A & $2(0.7 \%)$ \\
I & $2(0.7 \%)$ \\
$($ 一 $)$ & $2(0.7 \%)$ \\
(1) & $1(0.3 \%)$ \\
mixed: I, (1) & $1(0.3 \%)$ \\
mixed: only title, & $1(0.3 \%)$ \\
dates of letter & $1(0.3 \%)$ \\
第1章 & $1(0.3 \%)$ \\
第1節 & $1(0.3 \%)$ \\
第一場 & $1(0.3 \%)$ \\
第一節 & $1(0.3 \%)$ \\
total & $272(100.0 \%)$ \\
\hline
\end{tabular}

\begin{tabular}{|c|c|}
\hline \multicolumn{2}{|c|}{ 3rd level } \\
\hline only title & $125(88.6 \%)$ \\
\hline 1 & $4(2.8 \%)$ \\
\hline- & $4(2.8 \%)$ \\
\hline (1) & $2(1.4 \%)$ \\
\hline $\mathrm{A}$ & $2(1.4 \%)$ \\
\hline 【 title 】 & $1(0.7 \%)$ \\
\hline$\S 1$ & $1(0.7 \%)$ \\
\hline (1) & $1(0.7 \%)$ \\
\hline mixed: only title, $\uparrow$ & $1(0.7 \%)$ \\
\hline total & $141(100.0 \%)$ \\
\hline \multicolumn{2}{|c|}{ 4th level } \\
\hline only title & $6(75.0 \%)$ \\
\hline (1) & $1(12.5 \%)$ \\
\hline mixed: $(-),(1)$ & $1(12.5 \%)$ \\
\hline total & $8(100.0 \%)$ \\
\hline
\end{tabular}

two-level-table-of-contents type, and the other is the three-level-segment and two-level-tableof-contents type. This result also shows that the low-level segments tend to be omitted from the table of contents. $72.9 \%$ of Shinsho with three levels of segments have two levels of table of contents, as do five of the eight books with four levels of segments.

There is a one-level-segment and two-level-table-of-contents book and a two-levelsegment and three-level-table-of-contents book, which is shown in Table 3. Their tables of contents are detailed with reference not only to captions, but also to some sentences located at the heads of paragraphs. Therefore, the table of contents has more levels than depth of segments. 
Table 5. Combination of Captions

\begin{tabular}{c|r}
\hline \multicolumn{2}{c}{1 level } \\
\hline only title & $11(36.6 \%)$ \\
1 & $9(30.0 \%)$ \\
- & $5(16.6 \%)$ \\
I & $3(10.0 \%)$ \\
others & $2(6.6 \%)$ \\
total & $30(100.0 \%)$ \\
\hline
\end{tabular}

\begin{tabular}{|c|c|}
\hline \multicolumn{2}{|l|}{3 levels } \\
\hline I / 1 / only title & $37(27.8 \%)$ \\
\hline 第1章 / 1 / only title & $29(21.8 \%)$ \\
\hline 第一章 / / / only title & $12(9.0 \%)$ \\
\hline I / only title / only title & $7(5.2 \%)$ \\
\hline $1 / 1 /$ only title & $5(3.7 \%)$ \\
\hline 第1章 $I-I$ only title & $3(2.2 \%)$ \\
\hline 第一章 $/ ー$ I only title & $3(2.2 \%)$ \\
\hline I $/$ - I only titte & $2(1.5 \%)$ \\
\hline$-/ 1 /$ only title & $2(1.5 \%)$ \\
\hline only title / 1 / only title & $2(1.5 \%)$ \\
\hline only tithe / only title / only title & $2(1.5 \%)$ \\
\hline others & $29(21.8 \%)$ \\
\hline total & $133(100.0 \%)$ \\
\hline
\end{tabular}

only title / only titls

I/1

only title $/$ -

第一童

$-/$ only title

$1 / 1$

$-/ 1$

I

$-1$

第一章/ 1

others

total

\section{2 levels}

21 (16.0\%)

20 (15.2\%)

16 (12.2\%)

$13(9.9 \%)$

12 (9.1\%)

$9(6.8 \%)$

7 (5.3\%)

5 (3.8\%)

4 (3.0\%)

$3(2.2 \%)$

3 (2.2\%)

2 (1.5\%)

2 (1.5\%)

2 (1.5\%)

$12(9.1 \%)$

131 (100.0\%)

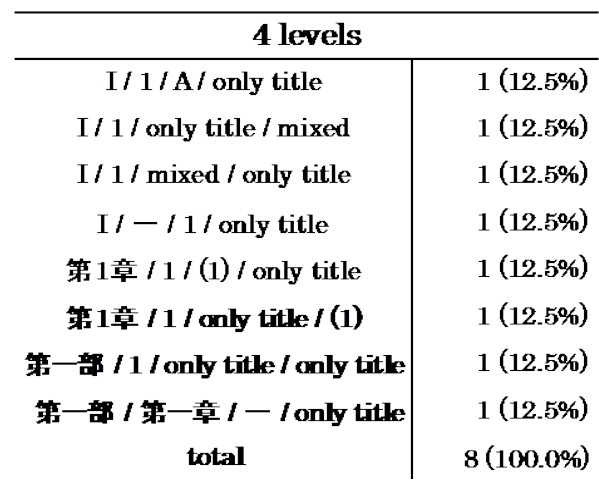

\section{Captions}

Table 4 shows the captions of each segment. $30.7 \%$ of the first level is expressed by I. Other frequently used captions include 第1章(“Chapter 1" written in a mix of kanji and Arabic numerals), 1, and 第一章(“Chapter 1” written in kanji). Captions of the second level can be broadly classified into two types. For the second level, $43.3 \%$ adopt 1 as a caption, and $37.8 \%$ have no caption symbols and are expressed by only the title of the segment. On the other hand, $88.6 \%$ of the third level is expressed by only the title.

Table 5 shows the combination of captions. There are 80 combinations; the combinations occurring only once in the first, second and third levels are omitted from the table to save space. No caption uses a point style such as 1.1.1, 1.1.2, and 1.1.3. The lowest level of segment tends to be expressed by only the title.

\section{Density of Segments}

Table 6 shows the density of segments. The values are plotted on a bar chart in Figure 1. In addition, Table 7 shows the mean, median, maximum value, minimum value, and standard deviation of the density of segments. The beginning point of a new segment appears on average 6.4 times in 20 pages. 
Table 6. Density of Segments

\begin{tabular}{clllllllllllllllllllll}
\hline density of segments & 0 & 1 & 2 & 3 & 4 & 5 & 6 & 7 & 8 & 9 & 10 & 11 & 12 & 13 & 14 & 15 & 16 & 17 & 18 & total \\
\hline number of books & 15 & 25 & 24 & 20 & 32 & 21 & 21 & 22 & 24 & 23 & 24 & 15 & 9 & 13 & 3 & 0 & 3 & 5 & 3 & 302
\end{tabular}

Table 7. Statistics of Density of Segments

\begin{tabular}{|c|c|c|c|c|c|}
\hline & mean & median & $\begin{array}{c}\text { maximum } \\
\text { value }\end{array}$ & $\begin{array}{c}\text { minimum } \\
\text { value }\end{array}$ & $\begin{array}{c}\text { standard } \\
\text { division }\end{array}$ \\
\hline density of segments & 6.47 & & 18 & & 4.22 \\
\hline
\end{tabular}

Table 8. The Decennial Number of Books

\begin{tabular}{crrrrrrrrr}
\hline year & 1910 & 1950 & 1960 & 1970 & 1980 & 1990 & 2000 & 2010 & \multicolumn{1}{c}{ total } \\
\hline number of books & 13 & 31 & 37 & 37 & 39 & 55 & 58 & 29 & 302
\end{tabular}

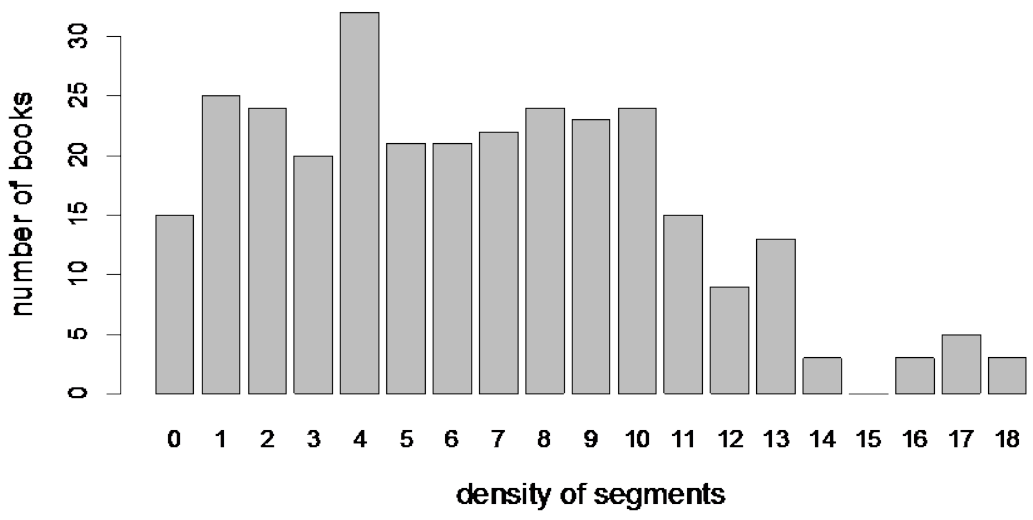

Figure 1. Density of Segments
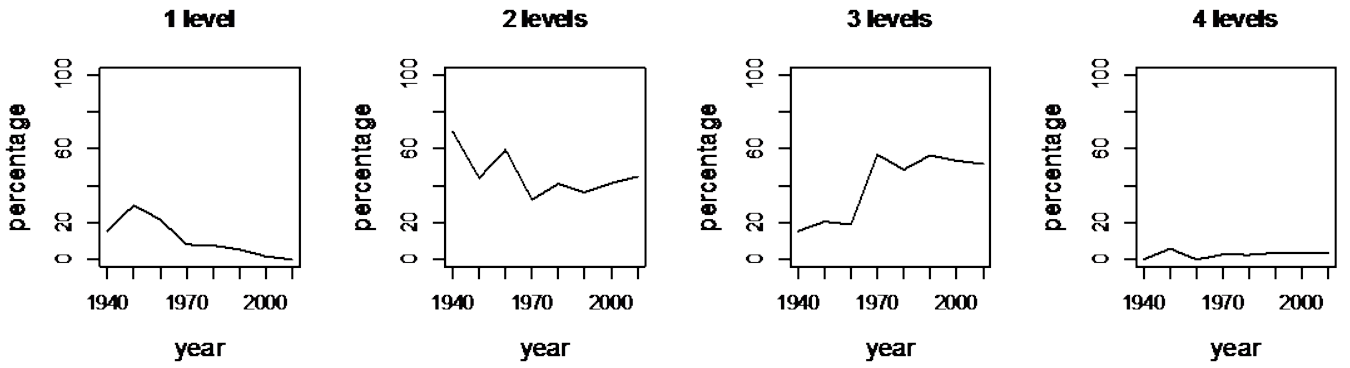

Figure 2. Depth of Segments

\section{Summary}

Shinsho are generally structured in two or three levels of segments, and the table of contents indicates mostly the top two levels. Although each segment has various captions, the highestlevel segment tends to be labelled with I. On the other hand, the lowest level tends to be expressed by only the title of the segment, without symbols. The starting point of a segment appears on average 6.4 times in 20 pages. 

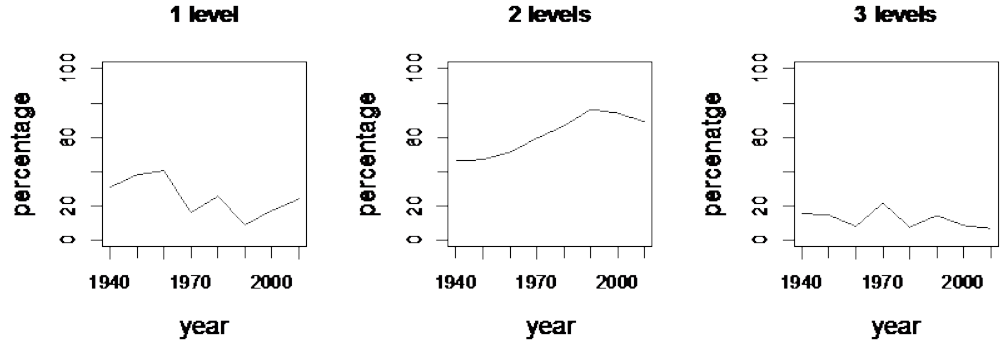

Figure 3. Levels of Table of Contents
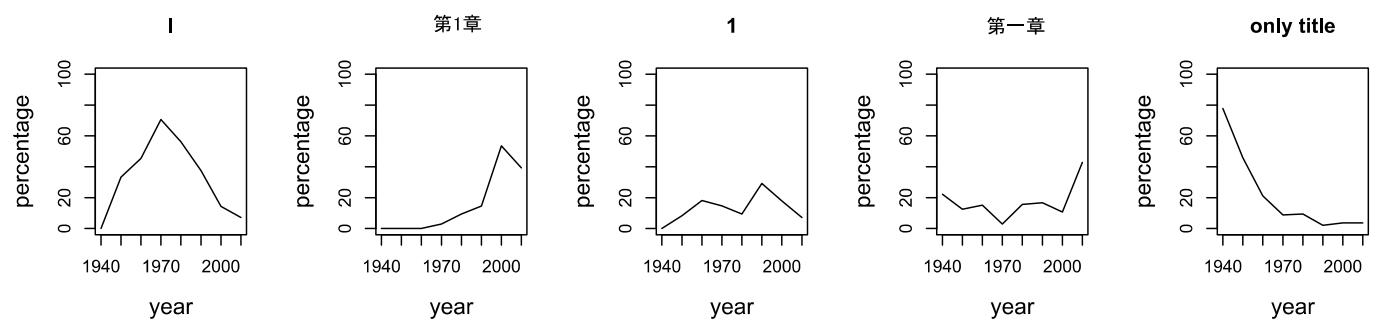

Figure 4. Captions of the First Level

\section{CHRONOLOGICAL OBSERVATIONS}

In this section, we analyse the chronological changes in the structural characteristics of Shinsho at 10-year intervals. Table 8 shows the number of books counted every 10 years. The Iwanami Shinsho series started in 1938, and the number of books in the 1940s includes five published in 1938 and 1939. The number of books in the 2010s is limited because we investigated books published by the end of 2014.

\section{Depth of Segments}

As shown in Figure 2, books with two levels of segments have been published from the 1940s to the present. On the other hand, books with only one level of segments were published in the 1940s and 1950s, but obviously declined after the 1950s. The percentage of three-level books is on the increase.

\section{Levels of Table of Contents}

Figure 3 shows an increase in tables of contents that go down to the second level. This trend corresponds to the increase in three-level-segment books shown in Figure 2. As mentioned before, books with three-level segments and two-level table of contents are one of the general types of Shinsho. Hence, these results reveal that the three-level-segment and two-level-tableof-contents style of Shinsho formed gradually.

\section{Captions}

We observed the top five captions of the first level: I, 第1章 1 , 第一章 and only the title. As shown in Figure 4, there is a rising trend for 第1章and 第一章 whereas I and only the title have been decreasing. The 1940s and 1950s saw the first levels expressed by only the title, but this style steadily disappeared from the captions of the first level. This trend matches the decrease of the one-level-segment books, indicated in Figure 2. The roman numeral I was mainly used until the 1990s, and thereafter replaced by 第1章and 第一章 


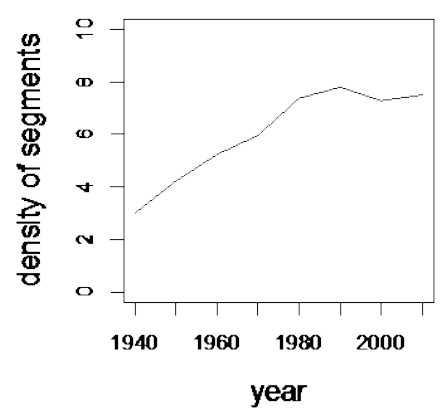

Figure 5. Density of Segments

Table 9. The Number of Books under NDC

\begin{tabular}{cccccccccccc}
\hline NDC & 0 & 1 & 2 & 3 & 4 & 5 & 6 & 7 & 8 & 9 & total \\
\hline \multirow{2}{*}{ number of books } & 4 & 27 & 46 & 96 & 47 & 18 & 17 & 17 & 9 & 21 & 502 \\
& $(1.3 \%)$ & $(8.9 \%)$ & $(15.2 \%)$ & $(31.7 \%)$ & $(15.5 \%)$ & $(5.9 \%)$ & $(5.6 \%)$ & $(5.6 \%)$ & $(2.9 \%)$ & $(6.9 \%)$ & $(100.0 \%)$
\end{tabular}

\section{Density of Segments}

Figure 5 shows the chronological change of density of segments. Since the foundation of Shinsho, the density of segments has shown a tendency to increase significantly. The average density of segments in the 1940s was 3.00, and in the 1990s it reached 7.80. The gap between the 1940s and the 1990s is 4.80 . This indicates a trend of the segment size becoming smaller and smaller.

\section{NDC OBSERVATIONS}

In this section, we analyse the association between the structural characteristics and the subject content using a subject classification system. This analysis is based on the hypothesis that the subject content influences the structure of the books. Table 9 shows the classification of 302 books. We used the Nippon Decimal Classification (NDC) system, which is based on the Dewey Decimal Classification. NDC has been adopted by most public libraries and many academic libraries in Japan. NDC classifies books into 10 categories by subject: 0 is general works, 1 is philosophy, 2 is general history, 3 is social science, 4 is natural science, 5 is technology and engineering, 6 is industry and commerce, 7 is arts, 8 is language, and 9 is literature.

Table 10 shows the relationship between the depth of segments and the subjects of books. There is an observable tendency in some categories. While $52.0 \%$ of books in Category 3 have three levels of segments, 51.8\% in Category 1 and 61.9\% in Category 9 have two.

Table 11 shows the relationship between the levels of the tables of contents and the subjects of books. It is difficult to find clear tendencies. Compared with other categories, only Category 9 has slightly more books with a table of contents having only the first level than books with a table of contents going down to the second level. 


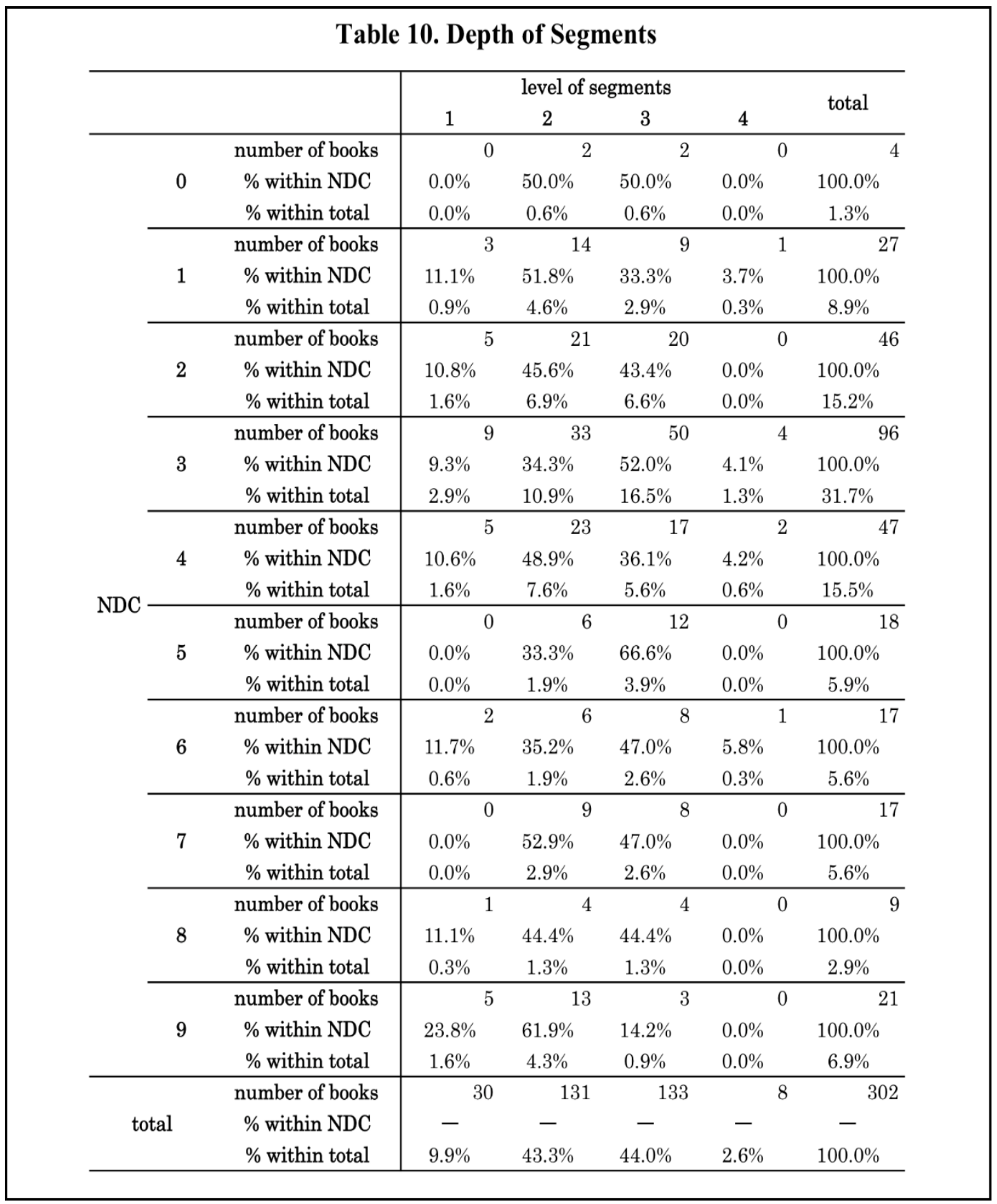

\section{Captions}

We observed the top five captions of the first level: I, 第1章 1, 第一章 and only the title. As shown in Table 12, books in Categories 4 and 6 tend to adopt I and 1. On the other hand, books in Category 3 tend to use I and 第1章 Lastly, 13 of the 41 books in Category 2 use 第一章 and 9 of the 16 books in Category 5 use I.

\section{Density of Segments}

Table 13 shows the mean value of density of segments. The value of 3.19 for Category 9 is markedly lower than the values for other categories. The density of segments in Category 9 is 
Table 11. Levels of Table of Contents

\begin{tabular}{|c|c|c|c|c|c|c|}
\hline & & & evel of tabl & contents & & total \\
\hline & & 1 & 2 & 3 & 4 & otal \\
\hline & number of books & $\mathbf{0}$ & 3 & 1 & & 0 \\
\hline $\mathbf{0}$ & \% within NIDC & $0.0 \%$ & $75.0 \%$ & $25.0 \%$ & $0.0 \%$ & $100.0 \%$ \\
\hline & \% within total & $0.0 \%$ & $0.9 \%$ & $0.3 \%$ & $0.0 \%$ & $1.3 \%$ \\
\hline & number of books & 9 & 12 & 5 & & 27 \\
\hline 1 & $\%$ within NIDC & $33.3 \%$ & $44.4 \%$ & $18.5 \%$ & $3.7 \%$ & $100.0 \%$ \\
\hline & $\%$ within total & $2.9 \%$ & $3.9 \%$ & $1.6 \%$ & $0.3 \%$ & $8.9 \%$ \\
\hline & number of books & 13 & 31 & 2 & & 46 \\
\hline 2 & \% within NDC & $28.2 \%$ & $67.3 \%$ & $4.3 \%$ & $0.0 \%$ & $100.0 \%$ \\
\hline & $\%$ within total & $4.3 \%$ & $10.2 \%$ & $0.6 \%$ & $0.0 \%$ & $15.2 \%$ \\
\hline & number of books & 17 & 65 & 14 & & 96 \\
\hline 3 & $\%$ within NDC & $17.7 \%$ & $67.7 \%$ & $14.5 \%$ & $0.0 \%$ & $100.0 \%$ \\
\hline & $\%$ within total & $5.6 \%$ & $21.5 \%$ & $4.6 \%$ & $0.0 \%$ & $31.7 \%$ \\
\hline & number of books & $\begin{array}{llll}9 & & & \end{array}$ & 33 & 5 & & 47 \\
\hline 4 & \% within NDC & $19.1 \%$ & $70.2 \%$ & $10.6 \%$ & $0.0 \%$ & $100.0 \%$ \\
\hline NDC & $\%$ within total & $2.9 \%$ & $10.9 \%$ & $1.6 \%$ & $0.0 \%$ & $15.5 \%$ \\
\hline & number of books & $\mathbf{0}$ & 16 & 2 & & 18 \\
\hline 5 & $\%$ within NDC & $0.0 \%$ & $88.8 \%$ & $11.1 \%$ & $0.0 \%$ & $100.0 \%$ \\
\hline & $\%$ within total & $0.0 \%$ & $5.2 \%$ & $0.6 \%$ & $0.0 \%$ & $5.9 \%$ \\
\hline & number of books & 4 & 9 & 4 & & 17 \\
\hline 6 & $\%$ within NDC & $23.5 \%$ & $52.9 \%$ & $23.5 \%$ & $0.0 \%$ & $100.0 \%$ \\
\hline & \% within total & $1.3 \%$ & $2.9 \%$ & $1.3 \%$ & $0.0 \%$ & $5.6 \%$ \\
\hline & number of books & 3 & 11 & 3 & & 17 \\
\hline 7 & $\%$ within NDC & $17.6 \%$ & $64.7 \%$ & $17.6 \%$ & $0.0 \%$ & $100.0 \%$ \\
\hline & $\%$ within total & $0.9 \%$ & $3.6 \%$ & $0.9 \%$ & $0.0 \%$ & $5.6 \%$ \\
\hline & number of books & 4 & 5 & 0 & & 0 \\
\hline 8 & \% within NDC & $44.4 \%$ & $55.5 \%$ & $0.0 \%$ & $0.0 \%$ & $100.0 \%$ \\
\hline & \% within total & $1.3 \%$ & $1.6 \%$ & $0.0 \%$ & $0.0 \%$ & $2.9 \%$ \\
\hline & number of books & 11 & 9 & $\mathbf{0}$ & & 21 \\
\hline 9 & $\%$ within NDC & $52.3 \%$ & $42.8 \%$ & $0.0 \%$ & $4.7 \%$ & $100.0 \%$ \\
\hline & $\%$ within total & $3.6 \%$ & $2.9 \%$ & $0.0 \%$ & $0.3 \%$ & $6.9 \%$ \\
\hline & number of books & 70 & 194 & 36 & & 302 \\
\hline total & \% within NDC & - & - & - & - & - \\
\hline & $\%$ within total & $23.1 \%$ & $64.2 \%$ & $11.9 \%$ & $0.6 \%$ & $100.0 \%$ \\
\hline
\end{tabular}

3.28 lower than the average density of segments. Category 5 has the largest value, and Category 9 the smallest, with a disparity of 4.8 .

\section{CONCLUSION AND OUTLOOK}

We have analysed the structural characteristics of Shinsho, including chronological developments, and the association between structural characteristics and the subject content of the books.

The overall characteristics of Shinsho are as follows. There are generally two types of structure in Shinsho: one is the two-level-segment and two-level-table-of-contents type, and the other is the three-level-segment and two-level-table-of-contents type. The characteristic of the caption is that the lowest level segments tend to be expressed by only the title. The starting point of a segment appeared on average 6.4 times in 20 pages.

The analysis of the chronological changes and the association between these characteristics and the subject content revealed several interesting points. First, the general form of Shinsho is three levels of segments and two levels of table of contents, and this form 
Table 12. Captions

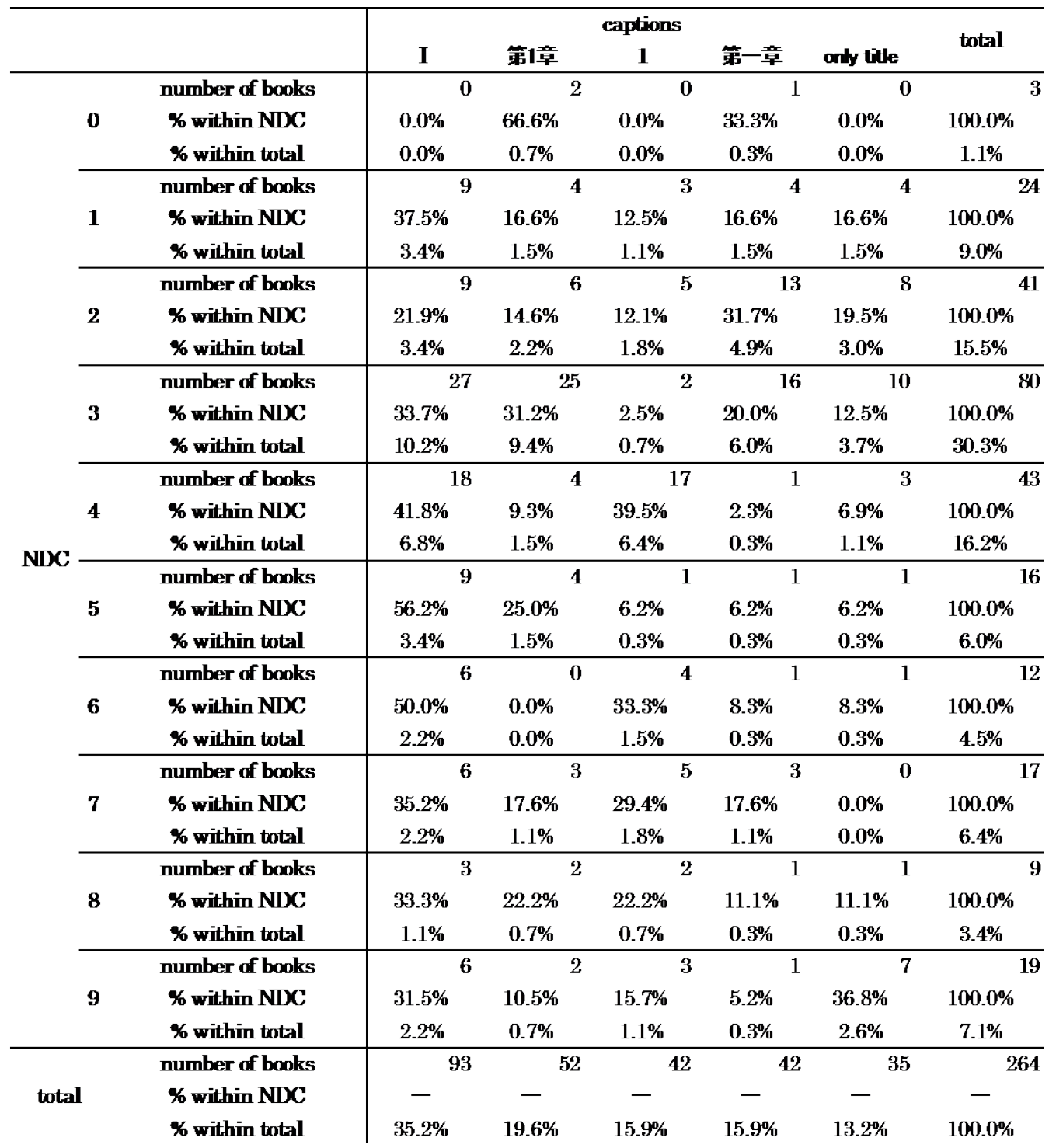

Table13. Density of Segments

\begin{tabular}{cllllllllll}
\hline NDC & 0 & 1 & 2 & 3 & 4 & 5 & 6 & 7 & 8 & 9 \\
\hline mean density of segments & 6.25 & 5.18 & 7.56 & 6.87 & 6.34 & 7.94 & 6.94 & 6.23 & 5.66 & 3.19
\end{tabular}

was established gradually. Second, while the density of the segments increased over time, books categorised as literature show a substantially lower density of segments.

These results suggest that the form of books is not fixed, even though we often conceive of books as having an absolutely definite form. The structure of Shinsho has changed over only 70 years. This result points out that the knowledge infrastructure has changed in the short term.

This paper can be regarded as the first step in a study of knowledge infrastructures. This study of Shinsho can be advanced in two potential directions. One is to extend the descriptive investigation to different groups of books, such as textbooks for students or encyclopedias. Like Shinsho, textbooks and encyclopedias are production-oriented books. A 
comparison of these books would clarify the variety and consistent structure of books as a knowledge infrastructure. The other is to research the connection between publishers, structure of books, and readers. This division into three factors is the framework that Chartier (1993) proposed and is introduced as the background of this study. This framework would enable us to identify how the structure of books affects reading.

\section{ACKNOWLEDGEMENTS}

This study is supported in part by the JSPS Grant-in-Aid for Scientific Research (B) JP25280120 “An Empirical Study of Changes in Print Media as Knowledge Infrastructure.”

\section{REFERENCES}

Chartier, Roger. (1993). L'ordre des livres. (Teruo Hasegawa, Trans.) Tokyo: E.H.E.S.C. Book. (Original work published 1992)

The Editorial Department of Iwanami Shoten Publishers (Ed.) (1988). Iwanami Shinsho no 50 nen. [The 50 years of Iwanami Shinsho]. Tokyo: Iwanami Shoten Publishers. [In Japanese]

Eisenstein, Elizabeth L. (1987). The printing revolution in early modern Europe (Sadanori Bekku, Trans.). Tokyo: Misuzu Shobo. (Original work published 1983)

McKenzie, D. F. (1986). Bibliography and the sociology of texts. London: British Library.

Martin, Henri Jean. (1994). Histoire et pouvoirs de l'écrit. (Lydia G. Cochrane, Trans.) Chicago: University of Chicago Press. (Original work published 1988) 